\title{
THE SPIRAL-UP INNOVATION OF PETROCHEMICAL COMPLEX IN GROUP OPERATION CONCERNING THE CASE OF RING (RESEARCH ASSOCIATION OF REFINERY INTEGRATION FOR GROUP-OPERATION) IN JAPAN
}

\author{
Kazuya Inaba \\ Graduate School-Management of Technology, Yamaguchi University, Yamaguchi, Japan
}

\begin{abstract}
The circumstances that surround the oil and petrochemical industry recently have been severe. Under such a severe competitive situation, oil and petrochemical companies came up with the idea of business cooperation in the same region in order to acquire global competitiveness. In this paper, the approach and ways of the high-level integration for group operation in petrochemical complex are analyzed, the meaning of RING projects is declared, and the economy that arises from group operation business is considered. Cooperation with some businesses would be effective for energy conservation and environmental measures, and would advance the possibility to achieve economies of public profit. Also, group operation would break the stoppage and promote innovations one after another in a petrochemical complex.

Keywords: petrochemical complex, oil and petrochemical industry, group operation, sustainable development, business cooperation, energy conservation, environmental measures, economies of public profit
\end{abstract}




\section{Introduction}

The circumstances that surround the oil and petrochemical industry recently have been severe. Oil and petrochemical companies are in the situation where they should deal with various problems. These subjects are global competitiveness setting between oil and petrochemical companies, sudden rise of price of raw material, response to environmental issues, minimization of resource energy consumption, security of safety technology, employment and economical contribution to the region, requirement to satisfy severe product quality standard, further upgrade and cost reduction in system of production, and construction of system of production to share at sustainable development etc.. In Japan, oil and petrochemical companies have taken up matters of energy saving measure, actions on environmental problems, security of global competitiveness, and restructuring of system of production etc..

In Europe, America, the Middle East, and East Asia (China, Taiwan, and South Korea), one company usually builds a large-scale factory, and consistently produces oil and petrochemical goods in the system of one company. Differently from it, two or more companies are concentrated in the coast landfills in Japan, and generally manufacture in the system of groups. The system of production in a petrochemical complex would be a medium-scale level if it sees worldwide. There is the reason by which this system was generated.

After World War II, capital was insufficient in Japan. Many companies advanced to the oil and petrochemical industry which seemed to have a big future. Small and medium scale factories were constructed. As a result, petrochemical complexes have been formed with the system of groups. They had competed and cooperated at times, and fought for the share with repeating excessive competition.

After the defeat of World War II, many oil companies excluding Idemitsu Kosan Co., Ltd. were organized for the supply of crude oil from European and American oil majors. They were devoted to refining oil and selling it only in Japan. Moreover, the oil market in Japan had been defended by restriction of the government. Such a system continued for years. Therefore, domestic oil companies had been aiming at improvement and efficiency of refining capacity. Their concentrating on technological development, cost reduction, and domestic share fought in the same industry had become a main activity. The construction of global competitiveness had been postponed for a while. However, Provisional Law on Importation of Specific Petroleum Products and Revision of volatile oil sales were abolished in 1996; the self-service gas station was permitted in 1998; and the Petroleum Act Law was abolished in 2001. After repealing these laws, the import liberalization of petroleum product had been taken, and cheap petroleum products had flown in from foreign countries. The sales price had not become the same, and free competition under market mechanism had started. As a result, the movement of industry reorganization had been accelerated.

In such a severe competitive situation, oil and petrochemical companies came up with the idea of business cooperation in the same region in order to acquire global competitiveness. In this paper, the approach and ways of the high-level integration for group operation in petrochemical complex are analyzed, the meaning of the plan is declared, and the economy that arises from the group operation business is considered. Cooperation with some businesses would be effective for energy conservation and 
environmental measures, and would advance the possibility to achieve economies of public profit. Also, group operation would break the stoppage and promote innovations of manufacturing technology one after another.

\section{1 - Change of oil and petrochemical industry in the world}

In the 1990's, oil and chemical companies of Europe and America have reorganized and consolidated their businesses based on the strategy of selection and focus. Extending strong fields further, they had been improving global competitiveness. In the petroleum industry, British Petroleum and Amoco Corporation had a plan to merge between 1998 and 2001, and became BP Amoco Chemical Corporation. Afterwards, ARCO was purchased. In oil companies in France and Belgium, TotalFinaElf was born. In the United States, there were two large scale merges of Exxon Mobile and Chevron Texaco Inc. As a result of having repeated merges and integrations $\square$ oil companies were integrated into mainly four companies, Exxon Mobile $\square$ Chevron $\square$ changed from Chevron Texaco Inc. in 2005. $\square$, BP, Royal Dutch Shell.

In the oil industry of Europe and America, these integrations don't only mean the efficiency, improvement and consolidation of oil refinement. Many oil companies have petrochemical industries downstream. If they could construct a consistent system of production from oil refinement to petrochemistry, the effect by integration would be larger. And the operation of supplying material to petrochemical sectors has occupied a big part of the profit in the oil refining industry. In the 1990's, the petrochemical section had changed for oil companies from a supplementary section to the section in which the profit is secured and growth will be expected in the future.

Petrochemical companies of chemistry origin also have attempted to reorganize and consolidate. Large mergers, alliances, and business integrations were done actively. However, different from petroleum industry, the integration of petrochemical companies of chemistry origin has another meaning.

On the one hand, the integration of oil companies which have petrochemical divisions have accomplished large plants in scale, consolidation, vertical integration, and possession of a lot of derivatives. They have adopted the strategy to pursue economies of scale and economies of scope. On the other hand, the integration of petrochemical companies of chemistry origin has consolidated their business into strong sectors in order to have global competitiveness. They have adopted the differentiation strategy. Changing from the strategy that possessed many sections and aimed at the general chemical company in the past, they have concentrated firm resources on strong businesses, separated weak departments with low share, and sold them off.

As well as the trend of reorganization and integration of European and American oil companies, a new movement has happened in Asian nations and the Middle East oilproducing countries. Especially, in the Middle East and China, there were movements to raise oil and petrochemical industry to a new industry in order to contribute to the region. It is expected that the promotion of oil and petrochemical industry would be able to produce employment in the region and contribute to the regional economy. They have intended to secure cheap raw materials, use the plentiful labor, and establish competitive advantage in factor conditions. They are planning on large-scale 
construction with the latest equipment to have cost competitiveness internationally. They are going to manufacture ethylene and general-purpose petrochemical products.

According to changes in world affairs, the environment that surrounds oil and chemical industry in Japan has changed greatly, too. In the Japanese oil industry before the 1990's, stabilization of price and limitation of excessive competition had been carried out by some laws. There was the fight of the share between enterprises on the closed domestic market. Though oil and petrochemical products were strongly influenced by international value, the customers were chiefly domestic enterprises and consumers. They didn't have a concern for international export, but the domestic market.

On the change of oil and chemical industry in the world and domestic deregulation, the reorganization and integration of oil companies was done in Japan. The Nippon Oil group came into existence from a merge of Nippon Oil and Mitsubishi Oil Co., Ltd. and the purchase of Koa Oil Co.1 in the refinement section. The megamerger of Nippon Oil Corp. and Japan Energy Corp. is scheduled in 2010. According to the flow of internationalization and deregulation, they carried it out to have global competitiveness. In Japan, oil enterprises have been reorganized and integrated other than mobile Exxon and Idemitsu Kosan Co., Ltd..

\section{Strengthening competitiveness of petrochemical complex in Japan}

Strengthening cost competitiveness is requested in oil and petrochemical enterprises in Japan. In the latter half of the 1990's, the merge and reorganization had advanced, and cost reduction had been attempted with efficiency improvement of production facilities. They had pulled out of unprofitable businesses. Positive investments in core business and growth business and participation in foreign complexes had made the business integration and competition stronger. However, the reorganization and integration of oil and petrochemical companies in Japan, if it is seen in the scale, is internationally the medium-scale one. It has faults that many operational companies are independent and production facilities have been distributed to many places. The equipment of oil and petrochemical companies in petrochemical complexes are widely distributed to eight places in the whole country. One company has production facilities in some complexes. The consolidation and expansion of manufacturing scale, efficiency improvement in manufacturing process, and reduction in cost of manufacturing are more necessary to obtain global competitiveness. But one company can only do so much alone.

Eight complexes were established in the 1950-70's. Looking at them now, their plants are internationally small-scale. In respect of the location on landfill in surface of the sea and acquirement of water for industrial use, there are restrictions as industrial ground. There are limits in the expansion in the future. The complexes are generally located in a place left from a large city. Therefore, the enterprises have difficulty in getting excellent manpower with the decrease in labor force in Japan. The example that one company consistently produces from upstream to downstream is few. Many operational companies usually get together and manufacture various derivatives. When these problems are taken into consideration, I cannot help saying that petrochemical complex in Japan is maintaining an extremely inefficient system of production.

But the complex management is discussed by a present standard here. Such a system was reflected on the intentions of past business management in Japan, which was 
caused by historical details. However, according to changes in international environments, it is necessary to improve their defects. It is difficult for one company to make an effort to rationalize. The conclusion under such a circumstance is an idea for the participants to exceed well of companies and aim at improvement of global competitiveness by integrated regional complex.

Based on this idea, the innovation would be caused in petrochemical complex of Japan by developing advanced united operational technology with group management.

In order to construct efficient systems of production for global competitiveness, oil and chemical corporations in Japan came to recognize the strategy, developing in the future, to exceed the frame of capital and enterprises, and cooperate with two or more businesses among oil factories or different types of business. To realize this, 20 companies in oil industry and chemical industry are concentrated. Under the Research Association of Technology Law, Research Association of Refinery Integration for Group-Operation (RING) was established in 2000. RING has acted group-operation programs in complex, which the Ministry of Economy, Trade and Industry has supported since 2000. In RING projects, they have tried to find new methods of integrated management, exceeding types of business and a frame of capital, developing some latest technologies, aiming at efficiency improvement and optimization. It is 1

Kazuya, Inaba., "Sengoki ni okeru Kowa Sekiyu no Kigyo Katudo - Gaisi Teikei kara Shin Nippon Sekiyu Seisei heno Gappei made - [The Enterprise Activities of Koa Oil after World War II - From Foreign Capital Alliances to Merge of Nippon Oil ]", Tiiki to Kigyo - Yamaguchiken Combinat Kanren

Kigyo wo tyusin ni [The Region and the Enterprise - Concerning the Enterprises related to Petrochemical Complex in Yamaguchi Prefecture - ], Tokuyama University Economic Research Institute Library, 2004, pp.1-33.important that one complex is thought of as one factory. If it is so, the integrated management could be practiced. As a result, new effects, economies and innovations by new technological development would be achieved. These practices are difficult for one company to do alone.

\section{Establishment of RING}

Petrochemical complexes of Japan have production facilities at a medium-scale level. It has been said that weak points of oil and petrochemical companies in Japan are halfway of cost reduction in medium-scale production, excessive competition, surplus of production scale, low degree of rate of profit. It is in the situation in which economies of scale cannot be requested.

And the equipment of one company is distributed to two or more districts. It is also difficult to consolidate these in one place. Many enterprises, concentrated in the same district, often belong to different capital groups. There are examples of producing same products by different manufacturing methods in the same district, too. In such a system, each company respectively has continued to conduct business actions, making decisions independently. Unfortunately, if the company is different, the organizational culture is also different and the spoken jargon tends to be dissimilar. There was an assumption not to communicate with each other easily in the situation. RING has called these things "Wall of person", "Wall of capital", and "Wall of geography". 
Looking at the technical side, oil and petrochemical companies in Japan had some problems and subjects. These were response to pollution and environmental issues, measures to conserve energy in the two Oil Crises, shift from general-purpose to high value-added product 2 , and cost reduction. They had dealt with them, and historically developed and accumulated technologies for them. Also, recycling technologies have been developed3. Environmental and saving resources technologies of Japanese enterprise have been evaluated throughout the world. These technologies in oil and petrochemical business are especially important.

Oil and petrochemical complexes of Japan have tried to improve and minimize the expenditure of resources and energy. In addition, they have promoted the response to environmental issues. They have made an effort to construct new systems of production which are clean and efficient with cost competitiveness. To achieve this, instead of past systems of an independent company, cooperation between businesses, exceeding the frame of oil factories and enterprise, has been necessary.

While such business cooperation is requested, RING was established in 2000. In RING, the research and development business, related to advanced united management, has been done between different types of business such as oil and petrochemical factory, etc. The first R\&D project (RING 1) had got good results of the proof of R\&D in the each district. It had resulted that strong unity was caused among complex enterprises through these activities. Following this, the second R\&D project (RING 2) was executed in 2003. Development of advanced, highly integrated technologies for reducing environmental burdens was performed there. In addition, the action to optimize entire petrochemical complex and carry out advanced function unification was executed in the third R\&D project (RING 3) in 2006. At present, such a business has been accomplished in most complexes in Japan, that is, in Kashima, Chiba, Kawasaki, Chita, Sakai Senboku, Mizushima, and Shunan.

One company perhaps tends to attempt single survival and optimization. Even if it notices the importance of cooperation, the priority level might be low. There are only two choices whether to execute it or not in one enterprise. Therefore, the government needs to put out a subsidy at first as the spark, and it is necessary to establish the thirdparty institution in order to give the motivation to business cooperation. It is important to build the organization to adjust common interest. The support of the government for RING projects is the first spark effect and function of backup. And the enterprises have recognized new possibilities in business cooperation. They would begin to mix well with them, and come to analyze a system of production with each other.

They would examine construction of system of production and technological development 2 This had the purpose to evade domestic excessive competition and pursuit of petrochemical manufacturers in East Asian nations.

3 Kazuya Inaba 'The Upgrade of petrochemical industry by recycling business Concerning the Case of the Chemical Recycling for Polyester in Teijin Limited-', PROCEEDINGS OF PRESENTATION

PAPERS, The 4th International Conference on Innovation \& Management, The Organizing Committee of ICIM2007, Yamaguchi University, 2007, pp265-70. 
Accommodating wasted gas, heat $\square$ and energy etc. And profits between enterprises, which one company cannot conceive, would begin to be recognized, and their interest would spread various contents such as treatment of waste, contribution to the region, joint power generation etc. Innovations have progressed in an upward spiral through cooperation between enterprises beyond the limit of single company business. The new idea of business cooperation has arisen one after another.

The new movement of business cooperation and group operation has been born in the complexes. In Chiba district, Idemitsu Kosan Co., Ltd. and Mitsui Chemicals, Inc. have promoted the business cooperation of oil and petrochemical since 2004. The production optimization of naphtha cracker with two companies and oil refinery plant has been examined in May, 2009. And in the Mizushima district, group operation of oil factory between Nippon Oil Corp. and Japan Energy Corp. began in June, 2006. After this cooperation, two companies had a plan to contract the basic agreement of business integration, which had been performed in December, 2008 between Nippon Oil Corp. and Nippon Mining Holdings, Inc., which is a holding company of Japan Energy Corp. The integration will be scheduled to be completed in July, 2010. Moreover, beyond wall of enterprises, there appeared the plans: the supply of electric power with hydrogen battery using hydrogen generated in the complex, and generated steam for airconditioning to the residence ground adjacent to the complex.

\section{Experimental studies in Kashima complex}

It is not easy to cooperate in businesses between two or more enterprises. To achieve business cooperation, there are problems of adjusting interests between enterprises. As assumption of a project like RING, a place for adjusting the interests should exist. Only after there is a place of discussion that exceeds wall of capital, the business cooperation like RING could be done. The prototype of the idea of RING project is the early movement in the Kashima complex. In the Kashima complex, the discuss-ground about problems of entire complex existed at first of the complex establishment in the latter half of the 1960's. Mitsubishi Chemical Corp., that is the participating company of Kashima complex, has thought about not only the region but also development of the chemical industry in the future. When there is such a background, the cooperative organization comes into existence.

There is the Corporate Liaison Council in Kashima Seaside Industrial Zone in the Kashima complex. It is composed of "General meeting" (all companies), "Operational committee" (nine district representative companies), "Environmental standing committee" (12 district representative companies), and "Harbors standing committee" (11 district representative companies). The occasion where senior executives of the enterprises can chat regularly (every two months) has been set. They have discussed common problems and aimed at the solution.

To exceed wall of capital, a place where top management can discuss regularly is necessary. Many problems in the field have been discussed by top managers. They have searched for solutions mutually. Such a system has been constructed since establishment. In the Kashima complex, participating companies always share recognition and consider each others interests and developments. 
Additionally, personal exchanges were actively done on site. Under "Factory Meeting Committee" in organization of the site of the Kashima complex, there are "Six Companies Committee", "Administration and Environmental Measures Report Committee," "Labor Report Committee," "Production Report Committee," "Technological Report Committee" ("Manager Committee" is under that), "Security Measures Report Committee." Together with "Factory Meeting Committee," there is "Security Measures Liaison Council" ("Manager Committee" is under that). According to the function of their jobs, personal interchanges with same departments of other companies have been promoted in the Kashima complex. The development and interests of the Kashima complex has been shared in the field. Under such a system, they have undertaken actions on some problems, every day operations, and adjustment of regular repair etc. since establishing the complex. They have known well the circumstances of other companies, and always have recognized the advantage of joint management. In addition to examination about rationalization of each company, for the purpose of strengthening competitiveness of the complex, they came to think some strategies. As a result, mainly in oil refinement and petrochemicals, they began to examine business integration utilizing mutual flexibility piping.

Kashima Oil Co. and Mitsubishi Chemical Corp., as RING 1, undertook "Development of Integrated Operation Technology Allowing Enhanced Utilization of Refinery and Petrochemical By-product" for the upgrade of mutual effective use of by-product material. And they succeeded to heighten the added value of by-products. In addition, the experimental study in which they efficiently collected the olefin fraction of petrochemical raw material from off-gas generated as a by-product by Kashima Oil, had been accomplished for three years from 2004. The result of this study is going to be used as high-value-added raw material in the petrochemical sector.

"Development of Integrated Refining Technology Allowing High Recovery of Cracked Off-gas" was carried out in RING 2. The technology collecting olefin fraction from offgas, which had not been evaluated only as a fuel, was expected to be applied widely to other complexes. The high level utilization of unused product will lead to strengthening cost competitiveness, and contribute to effective use of the resource. These technologies with cooperation of oil refinement and petrochemicals will improve competitive advantage in complexes. It is expected to contribute to energy conservation and environmental measures.

\section{Conclusion}

It is said that the RING project began from easy business collaborations at first and participating companies had not expected the result to joint operation too much. However, as RING projects have advanced, most enterprises have come to notice potential in the effect of group operation and business cooperation. The circle of RING extends through RING 1, 2, and 3. The speed of technological development in cooperating businesses has increased with acceleration. Innovations have occurred in an upward spiral. And, as time passes, reduction of $\mathrm{CO} 2$, energy conservation, and environmental measures have been paid attention to, and they have been involved in RING projects. If one company does it by itself, only the optimization for one company would be realized. Actions on these problems would be postponed when thinking from the priority level. However, in group operation and business cooperation, these would be problems to undertake first of all. 
The RING project is an attempt of joint operation and business cooperation in oil and petrochemical business. The project assumes current production facilities, capital tie, and business activities. On that assumption, it is necessary for two or more enterprises to cooperate and work on reduction of environmental burdens facing the world. Different from the strategy that one company pursues productivity and efficiency, same kind of effects may be achieved by cooperation between enterprises and different types of business. It will be possible for them to work also on environmental measures to share at sustainable development. In addition to economies of scale and economies of scope, economies of public profit will be added. When collaboration with many enterprises is achieved, the aspects to public interest will arise: joint energy use, efficiency improvement, regional contribution, establishment of safety technology, positive commitment to environmental measures, and cooperative treatment of waste etc. And enterprises will pay more attention to practices of public social activities: greening of the complex, ownership of joint power generating equipment, security cooperative relationship etc.

The goal of the RING project is to obtain global competitiveness in oil and petrochemical companies. When all technological developments are completed, much of reduction of energy use amount in oil refinement equipment etc. will be achieved, and it will be expected to increase production efficiency by the best flexibility of raw material and semi-finished products between oil refinery plants and different type of factories. And it is forecasted that they greatly contribute to reduction of $\mathrm{CO} 2$ exhaust. As a result of experimental studies that have been done up to now in RING projects, the amount of $\mathrm{CO} 2$ exhaust reduction is expected to reach 500,000 tons/year or more. In addition, the developed technology will be applied to other domestic industrial complexes, and therefore reduce $\mathrm{CO} 2$ further.

In general, the research projects a government subsidy do only the research. But, the RING project goes a step further from the research, and gives the proof of the research by taking to business. The project has the feature in which the result is actually obtained. Some technological results achieved in RING projects can be applied to other complexes. They will contribute to the upgrade of the complex. It is difficult to attempt group operation beyond wall of capital and wall of business. However, the accumulation of experiments in group operation would be applied to cooperation between different industries. And there is a possibility of utilization of the potential energy. 


\section{References}

Ikuo, Nomura., "Combinat Renaissance [Petrochemical Complex Renaissance] Kokusai Kyosoryoku Kyoka ni muketa Kodo Togo Unei Gijyutu Kaihatu [Development of highlevel Integrated Operation Technology for global competitiveness ]", Kagaku Kougaku [Chemical Engineering of Japan], vol.67, no.3, Kagaku Kougakukai [The Society of Chemical Engineers, Japan (SCEJ)], 2003, pp.174 - 7.

Masao, Yasuda., "Bunkai Off-gas Kodo Kaisyu Togo Seisei Gijyutu Kaihatu [Development of Integrated Refining Technology Allowing High Recovery of Cracked Off-gas]", Kagaku Kougaku [Chemical Engineering of Japan], vol.71, no.5, Kagaku Kougakukai [The Society of Chemical Engineers, Japan (SCEJ)], 2007, pp.272 - 5.

Takeo, Kikkawa., "Shigen Kaihatu Kyoso ni Katu Kagi 'Combinat Kodo Togo' [The Key that wins Resource Development Competition is "High-level Integration in Petrochemical Complex']", PRESIDENT 2009.1.12, PRESIDENT Inc., 2009, pp.153 5.

RING internal material. 